\title{
Solitary plasmacytoma of rib in a young adult - a rare case report
}

\author{
Abhinav Singh ${ }^{1}$, Ravisagar Patel ${ }^{1}$, Archana Singh ${ }^{2 *}$ Roma Patel ${ }^{2}$, \\ Sanjeev Devgarha ${ }^{3}$, Rajendra Mohan Mathur $^{3}$ \\ ${ }^{I}$ (Resident M.Ch CTVS, Department of cardiothoracic and vascular surgery, SMS medical college, Jaipur India) \\ $2^{*}$ (Clinical Associate Department of Obs.\&Gyn. Fortis Hospital, Jaipur ,India) \\ ${ }^{2}$ (Assistant Professor, Department of Anatomy, NIMS medical college, Jaipur , India) \\ ${ }^{3}$ (Professor \& Head of Department of cardiothoracic and vascular surgery, SMS medical college, Jaipur India)
}

\begin{abstract}
Solitary plasmacytoma of bone (SPB) is a rare disease, defined as clonal proliferation of plasma cells identical to those of plasma cell myeloma, which manifest as localised osseous growth with no evidence of disease dissemination. We report a case of solitary plasmacytoma of Right $6^{\text {th }}$ rib in 28-year-old male. The patient underwent complete en-bloc resection of the chest wall harbouring the tumour, ribs, muscles, and parietal pleura with reconstruction of chest wall. Patient is asymptomatic and in regular follow up .
\end{abstract}

Key Words: Chest wall, plasmacytoma, ribs, solitary tumor

\section{Introduction}

Solitary plasmacytoma of bone (SPB) is a rare localised lesion that accounts for only $5 \%$ of all plasma cell neoplasias ${ }^{[1-3]}$. It may present as the sole manifestation of plasma cell neoplasm, as a solitary plasmacytoma of the bone or as a consequence of multiple myeloma. Solitary plasmacytoma of rib usually shows destruction of the bone cortex with extension into the surrounding soft tissues. Plasmacytoma may be primary or secondary to the disseminated multiple myeloma and may arise from the osseous (medullary) or nonosseous (extramedullary) sites. Primary extramedullary plasmacytoma can be solitary or multiple ${ }^{[4]}$.SPB has been considered a genetic abnormality that can often change to multiple myeloma ${ }^{[5] .}$ Solitary plasmacytoma is rare as compared with multiple myeloma.

\section{Case Report}

A 28 year old nonsmoker male reported with swelling associated with right lower chest pain, gradual in onset, mild-to-moderate in nature, radiating to the back, since last 7 months. On local examination of the chest, there was a tender, solitary swelling of size $6 \mathrm{~cm} \mathrm{x} 4 \mathrm{~cm}$, on the right anterolateral chest wall arising from $6^{\text {th }}$ rib, firm, non mobile, fixed to chest wall but free from skin, with decreased right basal air entry. Rest of systemic examination was normal. Chest X-ray showed an extra pulmonary opacity around the right $6^{\text {th }}$ rib anteriorly [figure1] . On CECT of the chest a soft tissue density mass causing osteolytic destruction of right $6^{\text {th }}$ rib anteriorly [figure2], indenting the adjacent lung parenchyma with no pleural effusion or pleural thickening [figure3]. CECT of the skeletal spine and head and neck was normal. Bone marrow aspirate, trephine biopsy and flowcytometery revealed increased bone marrow plasma cells (reactive plasmacytosis) with no evidence of acute leukemia/lymphoma/ metastatic disease. Plasma cells in bone-marrow differential count was $5.8 \%$. Serum electrophoresis for $\mathrm{M}$ band proteins showed prominent $\mathrm{M}$-spike in gamma fraction. Immunofixation showed monoclonal IgA lambda. Urine for Bence Jones proteins was negative. Rest of the haematological investigations were normal. Pulmonary function test was suggestive of moderate restrictive pattern. CECT guided fine needle aspiration cytology was inconclusive.

Right anterolateral thoracotomy was done which revealed a well circumscribed tumor of $7 \mathrm{~cm} \times 5 \mathrm{~cm} \mathrm{x}$ $2 \mathrm{~cm}$ in size arising from the sixth rib anteriorly. En-bloc resection of the $5^{\text {th }}, 6^{\text {th }}$ and $7^{\text {th }}$ rib (harboring the tumour) with involved parietal pleura and muscles was done with $5 \mathrm{~cm}$ from the tumor margins. Lung tissue was not adherent to the tumor. Chest wall reconstruction was done with $25 \mathrm{~cm} \times 25 \mathrm{~cm}$ prolene mesh in double layer. Histopathology report was suggestive of plasmacytoma of the $6^{\text {th }}$ rib. Margins of the resected specimen were free from the tumor. Patient fulfilled the diagnostic criteria of solitary plasmacytoma of bone[1]:

I. A radiological lytic bone lesion with histological confirmation of plasma cell cytology.

II. Clinical and radiological evidence of a solitary lesion on skeletal survey.

III. An absence of myeloma cells and plasmacytosis of less than $10 \%$ in a bone marrow examination.

IV. Absence of anemia, hypercalcemia,or renal impairement.

V. Less than $2.0 \mathrm{~g} / \mathrm{dl} \mathrm{M}$ - protein in serum. 


\section{Discussion}

Localised solitary plasmacytoma of bone is a rare disease and is characterised by only one or two isolated bone lesions with no evidence of disease dissemination. Plasmacytomas can be divided into multiple, solitary osseous, and solitary extra-osseous or extramedullary plasmacytomas and rare as compared with multiple myeloma ${ }^{[6]}$ Localized SPB is a rare disease and has been considered to be curable with radiotherapy/surgical resection. This treatment is sufficient to achieve long term survival ${ }^{[5,7]}$. The incidence of SPB has been reported to be approximately $3 / 1000000$ annually in US ${ }^{[8]}$. SPB is an uncommon disease that accounts for only $5 \%$ of malignant plasma cell tumors. Most commonly tumor develops along spinal column with decreasing frequency in pelvis, ribs, upper extremeties, face, skull, femur and sternum ${ }^{[5]}$ Men are diagnosed twice as often as women. SPB occurs most commonly in African-Americans and least commonly in Asians and Pacific Islanders. Mean age at diagnosis is 55-65 yrs. According to the current recommendations, the detection of a monoclonal component in the serum or urine does not exclude a diagnosis of solitary plasmacytoma $^{[1,5]}$.Urine electrophoresis is an important test, because it may show abnormalities in a few patients even when the serum electrophoresis is normal.

In Japanese's literature, 14 cases of solitary plasmacytoma of rib origin have been described ${ }^{[9,10]}$. The ratio of male to female patient was approximately 1.3:1. The average age on presentation was 59.5 years with a range form 39 to 77 years $^{[5]}$. Our patient presented at a young age of 28 yrs. In past, radiation therapy was used as the primary treatment for solitary plasmacytoma. Mendenhall et al, reported a $6 \%$ local failure rate in patients with solitary plasmacytoma treated with doses of $40 \mathrm{~Gy}$ or above in contrast to $31 \%$ for doses below $40 \mathrm{~Gy}^{[8]}$ According to Bataille and Sany, the primary methods for treating solitary plasmacytoma were surgery with radiation therapy in 95 cases and surgery alone in 15 cases $^{[1,5]}$. Plasmacytoma almost always destroys bone. CECT scan and percutaneous needle biopsy are best investigations to diagnose chest lesions. The diagnosis is based on identification of the localized tumor composed of monoclonal plasma cells identical to those observed in multiple myeloma, and absence of the signs in favour of a disseminated form. In our case the needle biopsy was inconclusive .We subjected our patient to radical surgery after discussion with the tumor board of the hospital. Post-operative patient did well, he is asymptomatic and tumor free and in regular follow up with us. In cases were residual lesion persist adjuvant chemotherapy and radiotherapy should be prescribed ${ }^{[11,12]}$

\section{Conclusion}

Patients with solitary plasmacytoma originating in the rib have a feasibility of operative resection and radical treatment, and cure can be expected by adequate surgical resection of the tumor.

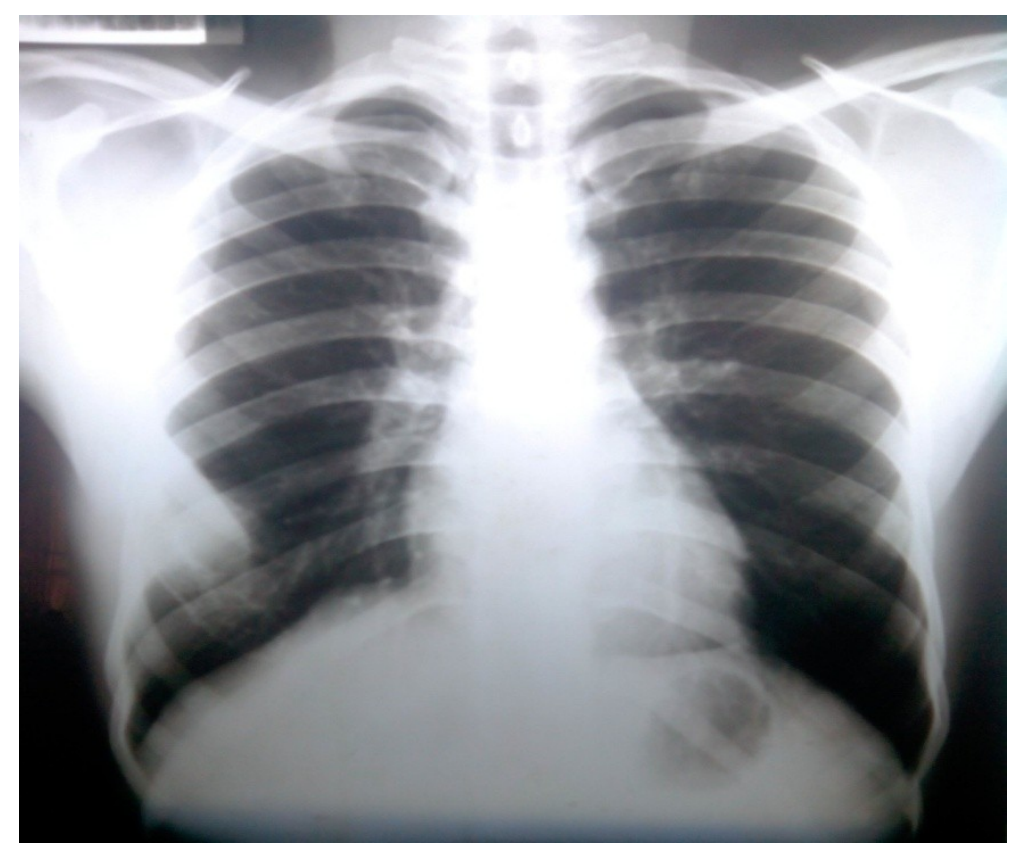




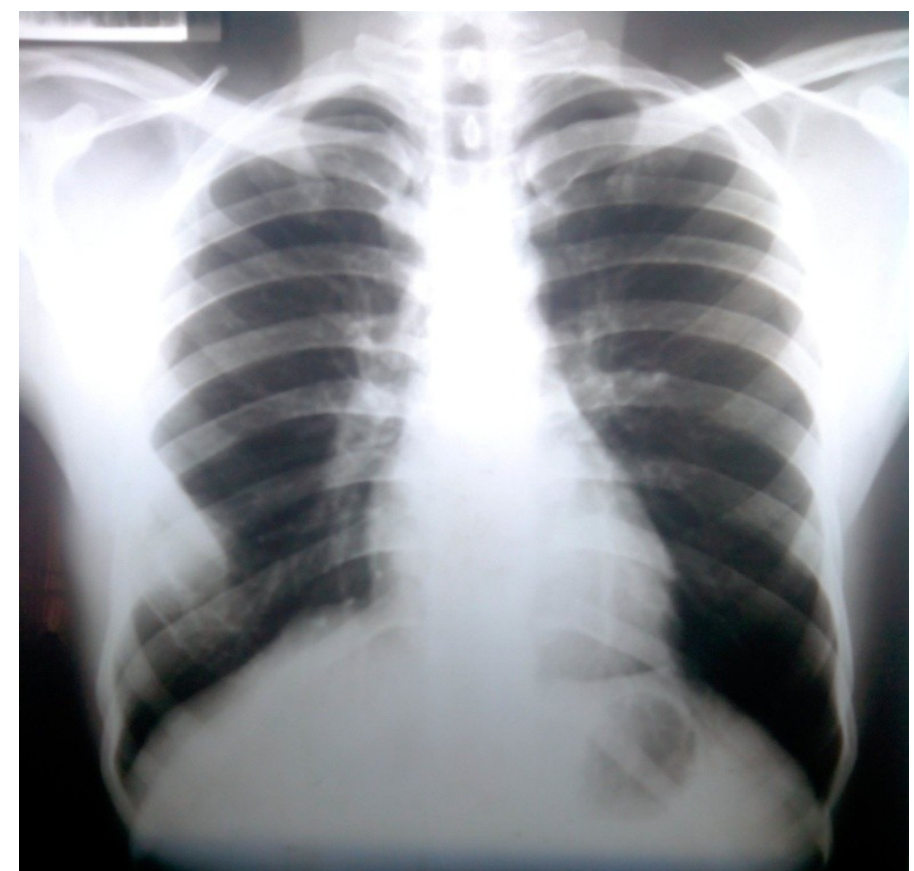

figure 1 . Chest $\mathrm{x}$ ray showing tumor of $6^{\text {th }}$ rib on right side

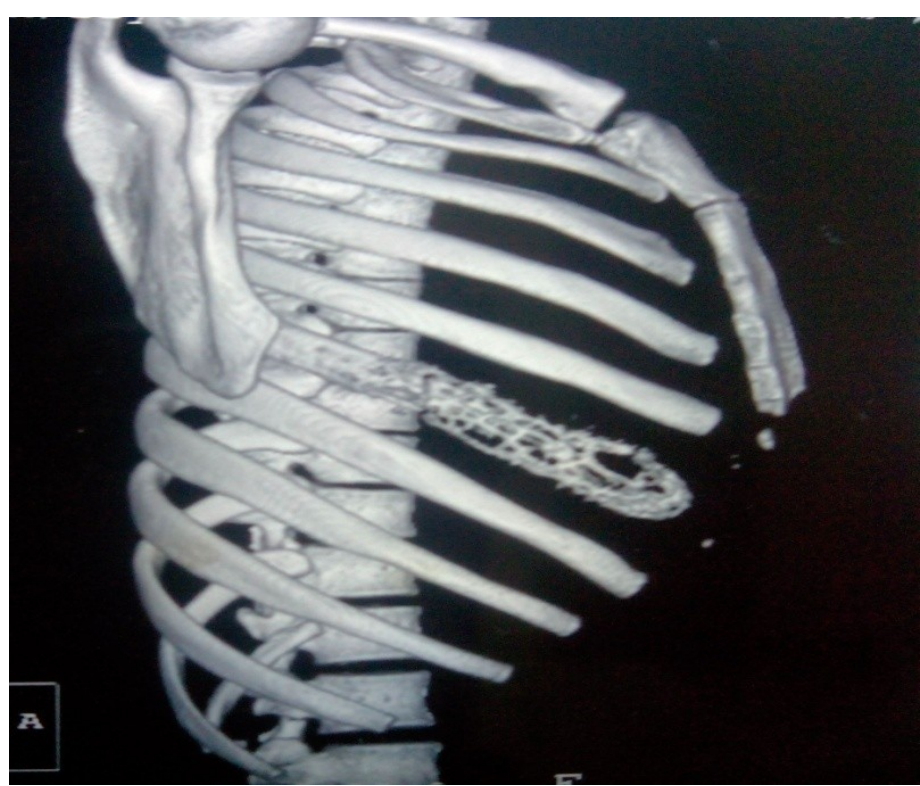

figure 2. Three dimensional reconstructed CT film showing destructing tumor of the $6^{\text {th }}$ rib on right side



CT film showing the rib tumor abuting the pleura but not invading the pulmonary parenchyma

Figure legend 1 . Chest $x$ ray showing tumor of $6^{\text {th }}$ rib on right side

Figure legend 2. Three dimensional reconstructed CT film showing destructing tumor of the $6^{\text {th }}$ rib on right side

Figure legend 3. CT film showing the rib tumor abuting the pleura but not invading the pulmonary parenchyma 


\section{References}

[1]. Bataille R, Sany J. Solitary myeloma: clinical and prognostic features of a review of 114 cases. Cancer.1981;48:845-51.

[2]. Goel G, Rai S, Naik R, Gupta A, Baliga P, Sinha R. Cytodiagnosis of extramedullary plasmacytomas. ActaCytol. 2010;54:255-8.

[3]. Bousnina S, Zendah I, Marniche K, Yalaoui S, El Mezni F, Megdiche ML, Chabbou A. Solitary plasmocytoma of the rib: A rare tumor not to miss. Rev Pneumol Clin. 2006;62:243-6.

[4]. Kadokura M, Tanio N, Nonka M, Yamamoto S, Kataoka D, Kushima M, et al. A Surgical case of solitary plasmacytoma of rib origin with biclonalgammopathy. Jpn J Clin Oncol. 2000;30:191-5.

[5]. Ooi GC, Chim JC, Au WY, Khong PL. Radiologic Manifestations of Primary Solitary Extramedullary and Multiple Solitary Plasmacytomas. AJR Am J Roentgenol. 2006;186:821-7.

[6]. AshiqMasood, HudhudKanan H, Hegazi AZ, Syed Gaffar. Mediastinalplasmacytoma with multiple myeloma presenting as a diagnostic dilemma. Cases J. 2008;1:116.

[7]. Fanning SR, Hussain MA, Perez-Zincer F. Plasmacytoma, extramedullary. E medicine. 2006

[8]. Mendenhall CM, Thar TL, Million RR. Solitary Plasmacytoma of bone and soft tissue. Int J RadiatOncolBiol Phys. 1980;6:1497501.

[9]. Hirai T, Hamada Y, Kanou T, Kobayashi J, Endo K, Morishita Y, et al. Solitary Plasmacytoma of the rib: A case report and review of the Japanese literature. Nippon Kyobu Geka Gakkai Zasshi.1995;43:205-9.

[10]. Hanawa T, Sawai S, Matsui T, Chiba W, Watanabe S, Matsubara Y, et al. A case of solitary plasmacytoma of the chest wall. Nippon KyobuShikkanGakkaiZasshi. 1994;32:616-20.

[11]. Rocco G, Robustellini M, Rossi G, Della Pona C, Solitary Bone Plasmacytoma of Rib presenting as superior sulcus tumour.

[12]. Incarbone M, Pastorino U. Surgical treatment of chest wall tumour. 